\title{
Safety and efficacy of occipital nerve stimulation for attack prevention in medically intractable chronic cluster headache (ICON): a randomised, double-blind, multicentre, phase 3, electrical dose-controlled trial
}

Leopoldine A Wilbrink*, Ilse F de Coo*, Patty G G Doesborg*, Wim M Mulleners, Onno P M Teernstra, Eveline C Bartels, Katja Burger, Frank Wille, Robert TM van Dongen, Erkan Kurt, Geert H Spincemaille, Joost Haan, Erik Wvan Zwet*, FrankJP M Huygen*, Michel D Ferrari*, for the ICON study group ${ }^{\prime}$

\section{Summary}

Background Occipital nerve stimulation (ONS) has shown promising results in small uncontrolled trials in patients with medically intractable chronic cluster headache (MICCH). We aimed to establish whether ONS could serve as an effective treatment for patients with MICCH.

Methods The ONS in MICCH (ICON) study is an investigator-initiated, international, multicentre, randomised, double-blind, phase 3, electrical dose-controlled clinical trial. The study took place at four hospitals in the Netherlands, one hospital in Belgium, one in Germany, and one in Hungary. After 12 weeks' baseline observation, patients with $\mathrm{MICCH}$, at least four attacks per week, and history of being non-responsive to at least three standard preventive drugs, were randomly allocated (at a 1:1 ratio using a computer-generated permuted block) to 24 weeks of occipital nerve stimulation at either $100 \%$ or $30 \%$ of the individually determined range between paraesthesia threshold and neardiscomfort (double-blind study phase). Because ONS causes paraesthesia, preventing masked comparison versus placebo, we compared high-intensity versus low-intensity ONS, which are hypothesised to cause similar paraesthesia, but with different efficacy. In weeks $25-48$, participants received individually optimised open-label ONS. The primary outcome was the weekly mean attack frequency in weeks 21-24 compared with baseline across all patients and, if a decrease was shown, to show a group-wise difference. The trial is closed to recruitment (ClinicalTrials.gov NCT01151631).

Findings Patients were enrolled between Oct 12, 2010, and Dec 3, 2017. We enrolled 150 patients and randomly assigned $131(87 \%)$ to treatment; $65(50 \%)$ patients to $100 \%$ ONS and $66(50 \%)$ to $30 \%$ ONS. One of the 66 patients assigned to $30 \%$ ONS was not implanted and was therefore excluded from the intention-to-treat analysis. Because the weekly mean attack frequencies at baseline were skewed (median 15.75; IQR 9.44 to 24.75) we used log transformation to analyse the data and medians to present the results. Median weekly mean attack frequencies in the total population decreased from baseline to $7 \cdot 38(2 \cdot 50$ to $18 \cdot 50 ; \mathrm{p}<0 \cdot 0001)$ in weeks $21-24$, a median change of $-5 \cdot 21(-11 \cdot 18$ to $-0 \cdot 19 ; \mathrm{p}<0 \cdot 0001)$ attacks per week. In the $100 \%$ ONS stimulation group, mean attack frequency decreased from $17.58(9 \cdot 83$ to 29.33$)$ at baseline to $9.50(3.00$ to 21.25$)$ at 21-24 weeks (median change from baseline $-4.08,-11.92$ to -0.25$)$, and for the $30 \%$ ONS stimulation group, mean attack frequency decreased from $15 \cdot 00(9 \cdot 25$ to $22 \cdot 33)$ to $6 \cdot 75(1.50$ to $16 \cdot 50$; $-6 \cdot 50,-10 \cdot 83$ to -0.08$)$. The difference in median weekly mean attack frequency between groups at the end of the masked phase in weeks $21-24$ was $-2.42(95 \%$ CI $-5 \cdot 17$ to $3 \cdot 33)$. In the masked study phase, 129 adverse events occurred with $100 \%$ ONS and 95 occurred with $30 \%$ ONS. None of the adverse events was unexpected but 17 with $100 \%$ ONS and eight with $30 \%$ ONS were labelled as serious, given they required brief hospital admission for minor hardware-related issues. The most common adverse events were local pain, impaired wound healing, neck stiffness, and hardware damage.

Interpretation In patients with MICCH, both $100 \%$ ONS intensity and $30 \%$ ONS intensity substantially reduced attack frequency and were safe and well tolerated. Future research should focus on optimising stimulation protocols and disentangling the underlying mechanism of action.

Funding The Netherlands Organisation for Scientific Research, the Dutch Ministry of Health, the NutsOhra Foundation from the Dutch Health Insurance Companies, and Medtronic.

Copyright (C) 2021 Elsevier Ltd. All rights reserved.

\section{Introduction}

Cluster headache is a highly disabling brain disorder, typically characterised by frequent attacks (up to eight times per day lasting 15-180 min) of excruciating, unilateral periorbital pain and ipsilateral facial autonomic symptoms, with or without restlessness. ${ }^{1,2}$ Up to $20 \%$ of patients with
Lancet Neurol 2021; 20: 515-25 See Comment page 498 ${ }^{*}$ Contributed equally $\dashv$ ICON study group members listed in the appendix Department of Neurology, Leiden University Medical Centre, Leiden, Netherlands (LA Wilbrink MD, I F de Coo MD, PG G Doesborg MD, J Haan MD, Prof M D Ferrari MD); Department of Neurology, Zuyderland Medical Centre, Heerlen, Netherlands (LA Wilbrink); Basalt Rehabilitation Centre, the Hague, Netherlands (I F de Coo); Department of Neurology, CanisiusWilhelmina Hospital, Nijmegen, Netherlands (W M Mulleners MD); Department of Neurosurgery, Maastricht University Medical Centre, Maastricht, Netherlands (O P M Teernstra MD, G H Spincemaille MD), Department of Anaesthesiology, Leiden University Medical Centre, Leiden, Netherlands (EC Bartels MD); Department of Anaesthesiology, Alrijne Hospital, Leiderdorp, Netherlands (K Burger MD); Department of Anaesthesiology, Diakonessenhuis Hospital, Zeist, Netherlands (FWille MD), Department of Anaesthesiology (RTM van Dongen MD) and Department of Neurosurgery (E Kurt MD), Radboud University Medical Centre Nijmegen, Netherlands; Department of Neurology, Alrijne Hospital, Leiderdorp, Netherlands (J Haan); Department of Biomedical Data Sciences, Leiden University Medical Centre, Leiden, Netherlands 


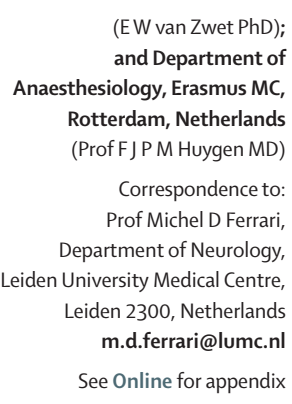

(EW van Zwet PhD); d Department of (ProfFJ P M Huygen MD)

Correspondence to: Prof Michel D Ferrari, tment of Neurology, See Online for appendix

\section{Research in context}

\section{Evidence before this study}

We searched PubMed on Jan 21, 2021, with the keywords "chronic cluster headache", "cluster headache", and "occipital nerve stimulation", without restrictions to language or publication year. Reviews were excluded. Of 72 returned items, we selected all peer-reviewed papers that reported cluster headache attack frequency or intensity at least 1 month after implantation. Papers on burst or extra-occipital stimulation protocols were excluded. In the case of neurostimulation for refractory headache, only data from patients with cluster headache were considered.

We identified 15 publications, from ten unique study populations, which fulfilled all selection criteria. Because of the wide heterogeneity of the baseline data, inclusion criteria, outcome measures, and follow-up time, a formal meta-analysis was not feasible. Instead, global results were summarised and presented as unbalanced means and range across studies. All studies were small, uncontrolled, and open-label and included in total 274 participants. Baseline periods were short (2-4 weeks). Not all main outcomes were available for all participants.

All studies showed positive outcomes. Follow-up durations were highly variable, both between studies and within studies between participants. Mean reduction in attack frequency was 50\% (range -25 to -80 ). Mean proportion of participants with more than $50 \%$ reduction in attack frequency was $62 \%$ (range 53-100). Mean change in headache intensity was $19 \%$ (range -49 to 8 ).

\section{Added value of this study}

Occipital nerve stimulation (ONS) showed promising results in small, uncontrolled, open-label studies. To the best of our knowledge, this is the first randomised, double-blind, controlled study to evaluate the clinical effects of ONS in a large population with medically intractable chronic cluster headache (MICCH). Because ONS induces local paraesthesia, complicating placebo comparison, we compared $100 \%$ ONS with $30 \%$ ONS. Both stimulation protocols were associated with similarly rapid and long-term sustained halving of the attack frequency. Half the participants achieved more than $50 \%$ reduction in attack frequency, and the attack intensity decreased by a third. More than $90 \%$ of participants would recommend ONS to other patients with MICCH.

The abrupt, marked, and up to 2 years of sustained improvement in symptoms after ONS treatment following a highly stable, 12-week, pre-treatment baseline observation period in patients with an unremitting history of highly disabling MICCH over many years, strongly supports a therapeutic effect of ONS, rather than a placebo effect. Moreover, known drivers for placebo response were unlikely to have had a substantial role. Finally, our results are in line with those of earlier small case series.

\section{Implications of all the available evidence}

ONS, even at low intensity, is a highly effective last-resort preventive treatment of chronic cluster headache not responding to conventional preventive medication. Our data will be useful for a broad range of health-care providers caring for patients with headache and pain in general. The results should also stimulate further biophysical and biomedical research to improve understanding of the underlying mechanisms of ONS and neuromodulation in general, to improve stimulation protocols, and to improve trial designs for testing treatment efficacy. cluster headache have chronic cluster headache, with no or only short ( $<3$ months) attack-free periods, in contrast to patients who have the episodic form. ${ }^{2}$

Attacks can be stopped with administration of subcutaneous sumatriptan or $100 \%$ oxygen inhalation. However, most patients also need preventive therapy. ${ }^{2}$ Up to $15 \%$ of patients with chronic cluster headache are refractory or intolerant to preventive medications, meaning that they have medically intractable chronic cluster headache (MICCH). ${ }^{3,4} \mathrm{MICCH}$ is a profoundly disabling disorder, particularly if attacks also occur at night and disturb sleep. Some patients even attempt to end their life by suicide. ${ }^{5}$

Invasive hypothalamic stimulation has shown promising efficacy in small studies without a control group (these have been reviewed elsewhere), ${ }^{6,7}$ but was sometimes associated with fatal complications. ${ }^{8}$ Moreover, although effective in migraine ${ }^{9}$ and episodic cluster headache, ${ }^{10}$ the monoclonal antibodies to calcitonin-gene-related peptide or its receptor were not effective in chronic cluster headache, ${ }^{11,12}$ underscoring the high unmet need for effective preventive treatment of this devastating disease.
Occipital nerve stimulation (ONS) is an invasive, non-destructive, reversible potential preventive treatment. Stimulation leads with electrodes are implanted subcutaneously bi-occipitally and connected to an implantable pulse generator (IPG; a battery-powered micro-electronic device that delivers electronic stimulation to the nervous system) that has been placed subcutaneously in the abdominal or gluteal region. ${ }^{13}$ The treatment rationale is based on human and animal studies showing convergence of cervical, somatic trigeminal, and dural trigeminovascular afferents on second-order nociceptors in the brainstem. ${ }^{2}$ Small uncontrolled studies have shown promising results. ${ }^{1422}$ Evidence from controlled studies is, however, scarce, primarily because ONS causes occipital paraesthesia, ${ }^{23}$ which complicates the feasibility of masked placebo-controlled trials.

Therefore, we compared the effects of $100 \%$ versus $30 \%$ of the individually accepted electrical dose of ONS in a randomised, double-blind study. ${ }^{13}$ Both intensities were hypothesised to cause similar paraesthesia, mitigating the risk of unmasking, while also showing differential efficacy, as has been described for a range of neurostimulation modalities..$^{24-27}$ 
Our study aimed to expand the preventive treatment options for patients with MICCH, further understanding of the mode of action of ONS and how it can be investigated in clinical trials, and further understanding of neurostimulation in general.

\section{Methods \\ Study design}

The ONS in MICCH (ICON) study was an investigatorinitiated, international, multicentre, randomised, doubleblind, phase 3, electrical dose-controlled clinical trial. The study consisted of the following study periods: a 12 -week baseline observation period; a device implantation and 10-day $10 \%$ ONS run-in treatment period; a 24 -week randomised, double-blind ONS treatment period with stepwise increase of ONS intensity (figure 1); and a 24-week open-label ONS treatment period. Participants were recruited from 12 tertiary headache clinics in the Netherlands, Hungary, Belgium, and Germany. After study completion, participants received regular outpatient care and an optional long-term follow-up for at least 3 years.

The study was designed and overseen by a steering committee (appendix p 11). Local ethics committees at each participating centre approved the study protocol, which was published previously. ${ }^{13}$ The most recent version of the protocol is accessible through clinicaltrial.gov (NCT01151631).

\section{Participants}

Participants were enrolled at four hospitals in the Netherlands, one in Belgium, one in Germany, and one in Hungary. Patients with suspected MICCH were referred by their attending neurologist and assessed for eligibility by a study neurologist. Inclusion criteria were as follows: chronic cluster headache; ${ }^{28}$ at least four attacks per week; minimum age of 18 years; a brain MRI completed within the past 1 year without relevant findings ${ }^{29}$ (ie, lesions that were probably related to cluster headache; appendix pp 4-5); and non-response to verapamil and lithium treatment in the past, intolerance, or contraindication to verapamil and lithium, along with non-response, intolerance, or contraindication to methysergide, topiramate, or gabapentin (a full list of inclusion criteria can be found in the appendix pp 4-5). ${ }^{3.4}$ Patients refrained from starting new cluster headache preventive treatments, including steroids, and did not change existing preventives from 4 weeks before baseline until after the double-blind study phase. Exclusion criteria included pregnancy, presence of cardiac pacemaker or other neuromodulatory devices, pyschiatric and cognitive disorders, serious drug habituation or overuse of acute-headache medication, and previous destructive surgery involving the C2 or C3 vertebrae or deep-brain stimulation (a full list of exclusion criteria can be found in the appendix pp 4-5). Written informed consent was obtained from all patients before entering the baseline study period. An independent data

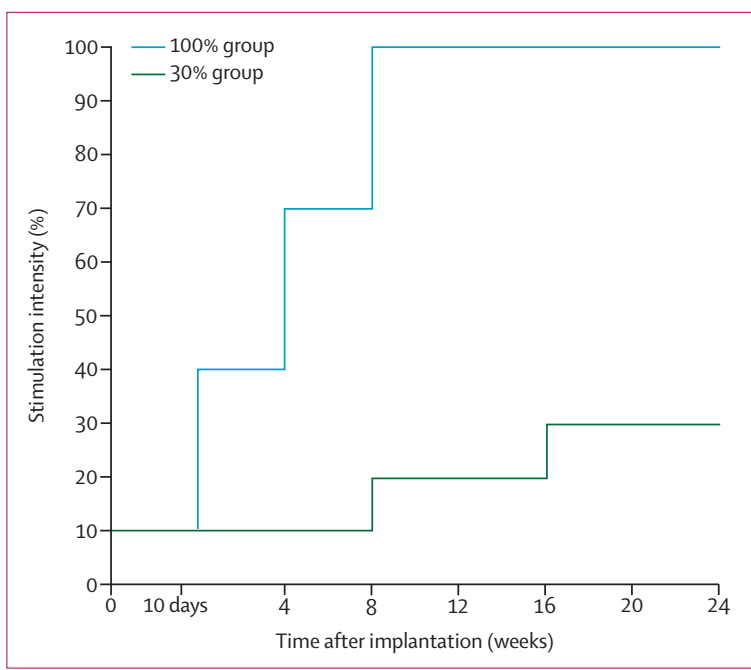

Figure 1: Study design and stimulation protocol in the run-in and double blinded periods

After randomisation, device implantation, and a 10-day run-in phase at $10 \%$ electrical-dose ONS, participants received double-blind $100 \%$ electrical-dose ONS (with stepwise increases up to $100 \%$ ONS by 8 weeks) or $30 \%$ electrical-dose ONS (with stepwise increases up to $30 \%$ by 16 weeks). ONS=occipital nerve stimulation. Percentage electrical doses refer to a range of voltages, with $0 \%$ as the intensity at which the patient started perceiving paraesthesia and $100 \%$ as the intensity that was $10 \%$ below the intensity the patient considered unpleasant.

safety monitoring board oversaw study progress and patient safety.

\section{Randomisation and masking}

After a prospective baseline observation of 12 weeks, patients still fulfilling all inclusion criteria ${ }^{13}$ (appendix pp $4-5$ ) were randomly allocated (1:1) to $100 \%$ or $30 \%$ of the individually accepted electrical ONS dose, with implantation centre as a stratification factor. Randomisation was done as a stratified, randomly varying block design (each block size randomly chosen to contain four to eight allocations), generated by an independent statistician, who had no further role in the study. After implantation, a nurse specialised in neurostimulator programming received the treatment allocation and set the appropriate stimulation parameters at each study visit, while maintaining masking. Medical professionals implanting the devices, participants, and study neurologists who were rating the outcome were all masked to assignment and were not involved in programming the neurostimulator.

\section{Procedures}

To ensure standardisation, the health professionals who were participating in the study and who were responsible for implanting the IPG received technical training from steering committee anaesthesiologists or neurosurgeons specialised in neuromodulation surgery (OPMT, GHS, and FJPMH). This training involved assistance during the first implantations at each centre. Neurosurgeons or pain anaesthesiologists did the surgery at each site. All had 


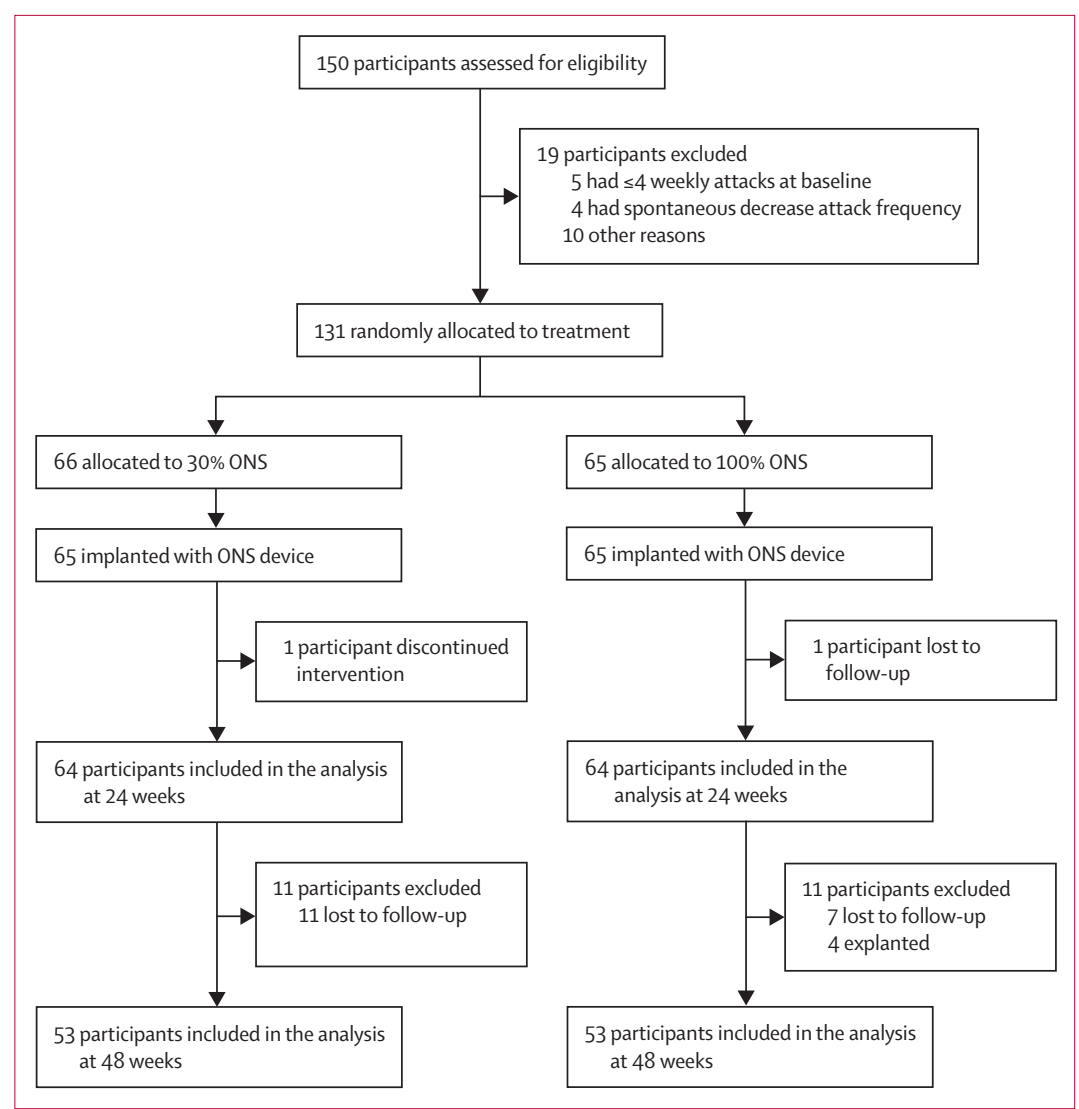

Figure 2: Trial design

ONS=occipital nerve stimulation. time stimulation intensities and medication were altered, and the patients were questioned on treatment satisfaction. Data, including attack frequency, use of medication, and physical and mental summary scores of the short-form survey 36 (SF-36; on a scale of 0-100, with 0 being the maximum disability and 100 representing no disability) to evaluate health changes were collected using web-based diaries and transmitted to an electronic database for analysis. ${ }^{13}$ All data remained confidential and were masked to medical staff and data analysts during the trial.

\section{Outcomes}

The primary outcome was the mean attack frequency (MAF) per week ${ }^{10,13,30}$ in the last 4 weeks of the masked study period (weeks 21-24 after the 10-day ONS run-in phase). Prespecified secondary outcomes ${ }^{13}$ reported here are the following: MAF for each 4-week period; weekly mean attack intensity (0-10 on the numeric rating scale, ${ }^{31}$ with 0 equating no pain and 10 the worst pain possible) at weeks 21-24 and weeks 45-48; proportion of participants with more than $50 \%$ reduction in MAF at week 24 and week 48 compared with baseline; patient satisfaction at week 24 and week 48 by asking the patients whether they would recommend ONS to other patients with MICCH on a 5-point Likert scale (strongly disagree, disagree, neutral, agree, or strongly agree); use of acute attack medication; use of abortive medication; presumed treatment allocation; analysis to identify people most likely to be responders; awareness of paraesthesias; economic evaluation (ie, comparison between the costs and outcomes of healthcare interventions); and adverse events. Proportion of participants with at least 30\% reduction in MAF at week 24 and week 48 compared with baseline was assessed as a post-hoc outcome.

Serious adverse events were defined according to EN ISO 14155-1. This definition implies that surgical interventions and hospital admissions (even for IPG replacement) were always labelled as serious adverse events, irrespective of whether the event was truly serious (ie, irrespective of whether the patient was truly severely ill). Use of abortive medication was assessed, but patient reporting on the use of abortive medication proved unreliable, and we therefore did not report it in this study. Additional secondary outcome measures ${ }^{13}$ that we did not report here and were analysed and presented separately were as follows: clinical characteristics of patients with at least $50 \%$ reduction in MAF (age, sex, smoking, age of onset of cluster headache, duration of chronic cluster headache, body-mass index, and response after 1 week); awareness of paraesthesia; economic evaluation; and long-term effectiveness and safety.

\section{Statistical analyses}

For our sample-size calculations, between-individual MAF variance at baseline was estimated from data in the literature $\mathrm{e}^{15}$ and our unpublished pilot study in 19 patients, 
who were on the waiting list for participation in the ICON trial, while the protocol was still under medical ethical review. To detect a clinically meaningful 35\% difference in MAF reduction (50\% reduction in the $100 \%$ stimulation group vs $15 \%$ reduction in the $30 \%$ stimulation group) at $90 \%$ power with a two-tailed significance of 0.05 , we needed 60 participants per group. To allow for $20 \%$ participant loss to follow-up, we aimed to include 144 patients. Further details concerning the sample size are described elsewhere. ${ }^{13}$

The primary study objective was to show a reduction in MAF in the last 4 weeks of double-blind treatment (week 21-24) compared with baseline across all patients and, if this objective was met, to show a difference in effect between $100 \%$ ONS and 30\% ONS to strengthen the conclusion of causality.

More formally, we tested several hypotheses sequentially, according to the closed-testing principle, ${ }^{32}$ proceeding to the next test only if statistical significance with a p-value lower than 0.05 was reached. This hierarchical approach ensured that the family-wise error was controlled at $5 \%$. First, we tested whether there was a reduction in MAF in the total study population. Then, if there was a reduction in the total study population, we examined whether a reduction in MAF was present in each treatment group separately and compared the treatment effect between the two groups.

Before unmasking, we noted that the distribution of the MAF was skewed. Therefore, we amended the protocol to use the logarithm of MAF $\left(\log _{\text {MAF }}\right)$ in the primary statistical analyses. In case the MAF at 21-24 weeks was equal to 0 , the minimum possible value of 0.25 (corresponding to one attack every 4 weeks) was added to allow for use of the logarithm. This amendment did not affect our sample size considerations.

The analyses included a linear regression analysis, with $\log _{\text {MAF }}$ in weeks $21-24$ as the dependent variable, $\log _{\text {MAF }}$ during baseline as the covariate, and treatment as the fixed factor. When loss to follow-up occurred, the last observation was carried forward. Although the statistical analyses were done using log-transformed data, we present the primary data using medians (with 25th and 75th percentiles) for better interpretability.

Linear regression was used to assess predictive factors of the natural logarithm of MAF in weeks 21-24. Repeated measures ANOVA was used to analyse SF-36 scores (physical and mental health summary scores) over time. Masking was analysed with a $\chi^{2}$ test between expected and actual stimulation group. Mean attack intensities were analysed using Student's t tests.

All analyses were done by intention to treat. In addition, to assess the effects of protocol violations, we also did a per-protocol analysis. Differences between groups at baseline were assessed by comparing means, medians, or percentages, depending on the type of variable. Data collection and quality checks were done with the ProMISe data management system of the Department of Biomedical Data Sciences of the Leiden University Medical Centre,

\begin{tabular}{|c|c|c|c|}
\hline & Total study group ( $n=130)$ & $100 \%$ ONS group $(n=65)$ & $30 \%$ ONS group $(n=65)$ \\
\hline Mean age, years & $44(13)$ & $44(13)$ & $44(13)$ \\
\hline Women & $47(36 \%)$ & $28(43 \%)$ & $19(29 \%)$ \\
\hline Men & $83(64 \%)$ & $37(57 \%)$ & $46(71 \%)$ \\
\hline Smokers ${ }^{*} \dagger$ & $73(57 \%)$ & $35(55 \%)$ & $38(59 \%)$ \\
\hline Alcohol consumers* $\ddagger$ & $53(42 \%)$ & $26(41 \%)$ & $27(43 \%)$ \\
\hline Coffee consumers*s & $104(82 \%)$ & $51(80 \%)$ & $53(84 \%)$ \\
\hline $\begin{array}{l}\text { Median body-mass } \\
\text { index }\end{array}$ & $25 \cdot 0(22 \cdot 5-29 \cdot 6)$ & $25 \cdot 7(23 \cdot 4-30 \cdot 0)$ & $24 \cdot 8(22 \cdot 1-29 \cdot 3)$ \\
\hline $\begin{array}{l}\text { Mean age of onset of } \\
\text { cluster headache, years } \boldsymbol{\Psi}\end{array}$ & $34(14)$ & $34(14)$ & $33(14)$ \\
\hline $\begin{array}{l}\text { Mean duration since } \\
\text { cluster headache } \\
\text { diagnosis, years || }\end{array}$ & $7(6)$ & $7(6)$ & $7(5)$ \\
\hline $\begin{array}{l}\text { Median duration of } \\
\text { chronic cluster headache, } \\
\text { years }^{* *}\end{array}$ & $4(2-7)$ & $4(2-8)$ & $4(2-7)$ \\
\hline \multicolumn{4}{|c|}{ Current use of acute therapy $\dagger \dagger$} \\
\hline Sumatriptan & $113(90 \%)$ & $57(90 \%)$ & $55(87 \%)$ \\
\hline Oxygen & $112(89 \%)$ & $59(92 \%)$ & $54(87 \%)$ \\
\hline \multicolumn{4}{|c|}{ Current use of prophylactic drugs at start of study $¥ \ddagger$} \\
\hline Verapamil & $39(30 \%)$ & $17(27 \%)$ & $22(34 \%)$ \\
\hline Lithium & $15(12 \%)$ & $7(11 \%)$ & $8(13 \%)$ \\
\hline Topiramate & $14(11 \%)$ & $8(13 \%)$ & $6(9 \%)$ \\
\hline Other\$s & $14(11 \%)$ & $8(13 \%)$ & $6(9 \%)$ \\
\hline $\begin{array}{l}\text { Median attack frequency } \\
\text { per week at baseline }\end{array}$ & $15 \cdot 75(9 \cdot 44-24 \cdot 75)$ & $17 \cdot 58(9 \cdot 83-29 \cdot 33)$ & $15 \cdot 00(9 \cdot 25-22 \cdot 33)$ \\
\hline $\begin{array}{l}\text { Mean attack intensity at } \\
\text { baseline, mean }(95 \% \mathrm{Cl})\end{array}$ & $7 \cdot 58(7.31$ to $7 \cdot 85)$ & $7.67(7.32$ to 8.03$)$ & 7.48 (7.07 to 7.89$)$ \\
\hline \multicolumn{4}{|c|}{ 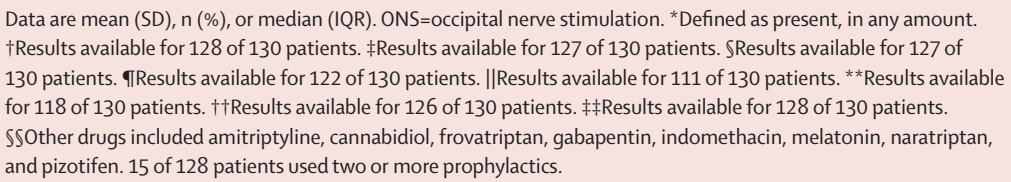 } \\
\hline
\end{tabular}

Leiden, Netherlands. SPSS version 23.0 and R version 3.5.1 were used for all statistical analyses.

The trial is registered at ClinicalTrials.gov (NCT01151631).

\section{Role of the funding source}

The funder of the study had no role in study design, data collection, data analysis, data interpretation, or writing of the report.

\section{Results}

From Oct 12, 2010, to Dec 3, 2017, 150 patients were enrolled and 131 randomly allocated to treatment (appendix p 6). The enrolment was protracted due to temporary reimbursement issues for devices and implantations (appendix p 8). After 12 weeks of baseline observation, $131(87 \%)$ patients still met all the inclusion criteria and were randomly assigned to $100 \%$ ONS (65 patients) or $30 \%$ ONS (66 patients; figure 2). One of the participants who was randomly assigned to the $30 \%$ ONS group did not receive an implanted device because of alcohol 


\begin{tabular}{|c|c|c|c|}
\hline & $\begin{array}{l}\text { Total study population } \\
(\mathrm{n}=130)\end{array}$ & $\begin{array}{l}100 \% \text { ONS stimulation } \\
(\mathrm{n}=65)\end{array}$ & $\begin{array}{l}30 \% \text { ONS stimulation } \\
(\mathrm{n}=65)\end{array}$ \\
\hline \multicolumn{4}{|c|}{ MAF per week at weeks 1-4, median (IQR)* } \\
\hline Value & 9.62 (3.81 to 18.44$)$ & $10 \cdot 50(4.00$ to 19.00$)$ & 8.50 (3.50 to 18.25$)$ \\
\hline Change from baseline $\dagger$ & $-4.63(-10.56$ to -0.94$)$ & NA & NA \\
\hline $\begin{array}{l}\text { Relative change (\%) } \\
\text { from baseline }\end{array}$ & $-36.81(-60.62$ to -7.92$)$ & NA & NA \\
\hline \multicolumn{4}{|c|}{ MAF per week at weeks 21-24, median (IQR) } \\
\hline Values & $7.38(2.50$ to 18.50$)$ & 9.50 (3.00 to 21.25) & $6.75(1.50$ to $16 \cdot 50)$ \\
\hline Change from baseline ${ }^{\dagger}$ & $-5 \cdot 21(-11 \cdot 18$ to -0.19$)$ & $-4.08(-11.92$ to -0.25$)$ & $-6.50(-10.83$ to -0.08$)$ \\
\hline $\begin{array}{l}\text { Relative change (\%) } \\
\text { from baseline }\end{array}$ & $-42.56(-80.05$ to -1.80$)$ & $-41.06(-74.41$ to $-2 \cdot 33)$ & $-46.00(-83.58$ to -0.89$)$ \\
\hline \multicolumn{4}{|c|}{ MAF per week at weeks $45-48$, median (IQR)* } \\
\hline Value & 7.62 (1.31 to 20.75$)$ & 9.50 (1.50 to 21.50$)$ & $6.50(1.25$ to $17 \cdot 50)$ \\
\hline Change from baseline $\dagger$ & $-5.92(-11.49$ to -0.13$)$ & NA & NA \\
\hline $\begin{array}{l}\text { Relative change (\%) } \\
\text { from baseline }\end{array}$ & $-50 \cdot 45(-89.73$ to -1.65$)$ & NA & NA \\
\hline \multicolumn{4}{|c|}{$\geq 50 \%$ responders $\Psi, \%(95 \% \mathrm{Cl})^{*}$} \\
\hline Week 21-24 & $44 \cdot 6(36 \cdot 3$ to $53 \cdot 2)$ & $44 \cdot 6(33 \cdot 2$ to $56 \cdot 7)$ & $44 \cdot 6(33 \cdot 2$ to $56 \cdot 7)$ \\
\hline Week 45-48 & $50.0(41.5$ to 58.5$)$ & NA & NA \\
\hline \multicolumn{4}{|c|}{$\geq 30 \%$ responders $\uparrow, \%(95 \% \mathrm{CI}) \|$} \\
\hline Week 21-24 & $55 \cdot 4(46.8$ to $63 \cdot 7)$ & $53.8(41.9$ to $65 \cdot 4)$ & $56 \cdot 9(44 \cdot 8$ to $68 \cdot 2)$ \\
\hline Week 45-48 & $55 \cdot 4(46 \cdot 8$ to $63 \cdot 7)$ & NA & NA \\
\hline \multicolumn{4}{|c|}{ Mean attack intensity at weeks $1-4$, mean $(95 \% \mathrm{Cl})^{*}$} \\
\hline Value & 5.96 (5.54 to 6.38 ) & NA & NA \\
\hline Change from baseline & $-1.62(-2.01$ to -1.23$)$ & NA & NA \\
\hline $\begin{array}{l}\text { Relative change (\%) } \\
\text { from baseline }\end{array}$ & $-21.02(-25.99$ to -16.05$)$ & NA & NA \\
\hline \multicolumn{4}{|c|}{ Mean attack intensity at weeks $21-24$, mean $(95 \% \mathrm{Cl})^{*}$} \\
\hline Value & $5.57(5.07$ to 6.06$)$ & $-1 \cdot 85(-2 \cdot 37$ to $-1 \cdot 33)$ & $-2.18(-2 \cdot 89$ to $-1 \cdot 46)$ \\
\hline Change from baseline & $-2.01(-2.45$ to -1.58$)$ & NA & NA \\
\hline $\begin{array}{l}\text { Relative change (\%) } \\
\text { from baseline }\end{array}$ & $-27 \cdot 19(-32 \cdot 83$ to $-21 \cdot 55)$ & NA & NA \\
\hline \multicolumn{4}{|c|}{ Mean attack intensity at weeks $45-48$, mean $(95 \% \mathrm{Cl})^{*}$} \\
\hline Value & $5 \cdot 14(4 \cdot 62$ to $5 \cdot 66)$ & NA & NA \\
\hline Change from baseline & $-2 \cdot 44(-2 \cdot 94$ to -1.93$)$ & NA & NA \\
\hline $\begin{array}{l}\text { Relative change (\%) } \\
\text { from baseline }\end{array}$ & $-31.68(-37.99$ to -25.37$)$ & NA & NA \\
\hline \multicolumn{4}{|c|}{ 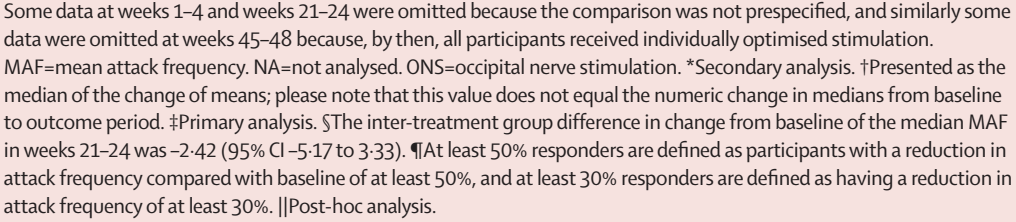 } \\
\hline
\end{tabular}

intoxication on the day of the planned surgery, and was excluded from the intention-to-treat analysis. Baseline characteristics did not differ between treatment groups (table 1). Because the dropout rate (two [1.5\%] of 131 patients) was substantially lower than anticipated, recruitment was halted at 131 patients, of which 122 patients were recruited from Dutch centres.

The 24-week follow-up data were collected and locked by Oct 30, 2018. One participant in each treatment group was lost to follow-up, and their data were analysed using last observation carried forward. In 20 participants, the stimulation intensities were set lower than prespecified, because they were otherwise perceived to be too strong.

We present MAFs, responder rates (as defined in table 2), and changes from baseline (table 2 and figure 3). At baseline, weekly MAFs were skewed; some participants had a high attack frequency. For most participants, individual MAFs remained stable across the 12-week baseline observation period (figure 3A). These results were supported by a formal repeated-measurements analysis; taking $\log _{\mathrm{MAF}}$ as the outcome, taking the time periods as the only continuous predictor, and adding a random intercept per patient to account for the correlation between measurements in the same person, the results showed no significant difference across the 12 baseline weeks $(\mathrm{p}=0 \cdot 38$; appendix pp 23-24).

After ONS onset, median weekly MAF in the total population was 7.38 (IQR 2.50 to $18 \cdot 50$ ), a median decrease of $-5 \cdot 21$ (IQR $11 \cdot 18$ to $-0 \cdot 19 ; \mathrm{p}<0 \cdot 0001$ ). The median decrease in the $100 \%$ group was -4.08 $(-11.92$ to -0.25$)$ and in the $30 \%$ ONS group was $-6 \cdot 50$ $(-10 \cdot 83$ to $-0 \cdot 08)$. We observed no difference in MAF decrease between weeks 21 and 24 compared to baseline between treatment groups $(-2 \cdot 42 ; 95 \% \mathrm{CI}-5 \cdot 17$ to $3 \cdot 33)$. In weeks $1-4$, median weekly MAF in the total study population had already reduced. Median relative change in MAF in the total study population in weeks 21-24 was $-42 \cdot 56 \%$ (IQR $-80 \cdot 05$ to $-1 \cdot 80$ ), with a median change of $-41.06(-74.41$ to $-2 \cdot 33)$ in the $100 \%$ ONS group and $-46.00(-83.58$ to -0.89$)$ in the $30 \%$ ONS group. Median weekly MAF did not decrease much further during the open-label phase. We saw no significant differences between study sites (appendix p 9). In the total study population, approximately half the participants had at least a 50\% reduction in MAF at weeks 21-24 and weeks 45-48. Overall, seven participants were attack free in weeks 1-4, nine were attack free in weeks 21-24, and 16 were attack free in weeks 45-48. Per-protocol analysis of the primary outcome showed similar results as the intention-to-treat analysis (appendix pp 12-53).

We present mean attack intensities and intensity changes (table 2, figures 4A-B). At baseline, the weekly mean attack intensities were highly stable across 12 weeks, except for a few participants. The weekly mean attack intensity in the total population decreased from baseline in weeks 1-4, weeks 21-24, and weeks 45-48. Results were similar in both groups (figure 4B).

At week 24, 91\% of participants with available scores would recommend ONS to other patients, with $74 \%$ of participants willing to strongly recommend ONS. 5\% of participants would not recommend ONS and a further $5 \%$ had a neutral opinion. At 48 weeks $97 \%$ of participants would recommend ONS, with $73 \%$ of participants willing to strongly recommend the treatment. The recommendation rates were similar in both groups. Efficacy and tolerability results in participants without satisfaction 
scores were not different from those with satisfaction scores, rendering selection bias unlikely.

The mean physical health summary score increased from 52 (95\% CI 49-56) at baseline to 58 (54-63) at 24 weeks and 62 (58-66) at 48 weeks (appendix p 2; $\mathrm{p}<0.0001$ over time between baseline and 48 weeks in the total study group). The mean mental health summary score increased from $50(45-55)$ at baseline to 58 (53-63) at 24 weeks, and $61(56-65)$ at 48 weeks (appendix p 3; $\mathrm{p}<0.0001)$. Results were similar in both stimulation groups between baseline and 12 months (mean physical health summary score $\mathrm{p}=0.88$; mean mental health summar score $\mathrm{p}=0 \cdot 77$; appendix pp 2-3).

At the end of the 24-week double-blind treatment period, $61 \%$ of patients and $59 \%$ of neurologists correctly guessed treatment assignment.

59 serious adverse events occurred in 46 participants (table 3). Of these, 35 serious adverse events in 31 participants (given that one patient had a hardware problem both in the masked and open phase) were hardwarerelated-ie, replacement of empty IPGs or dislocation, failure, or fracture of electrodes or leads. The most severe adverse event occurred in a patient with multiple vascular risk factors, who suffered a right-middle cerebral artery transient ischaemic attack 1 month and 15 days after implantation and resumption of anti-thrombotic treatment. This event was considered to be unrelated to the procedure or the device by the investigator. No deaths were recorded. The number of serious adverse events was similar in both groups.

\section{Discussion}

ONS was associated with a major, rapid, and sustained improvement of severe and long-lasting $\mathrm{MICCH}$, both at high and low intensity. MICCH attack frequency was halved and attack intensity was reduced by a third. At 24 weeks, roughly half the participants had a $50 \%$ or higher reduction in attack frequency and 16 (12\%) of 130 had no MICCH attacks. The beneficial effect of ONS started within a few weeks of treatment and was sustained throughout the 48 -week study period. ONS was well tolerated, and more than $90 \%$ of participants would recommend the therapy to other patients.

Because the results showed no significant difference between treatment groups, we cannot exclude that improvement could be partially due to the placebo effect. However, such an abrupt, pronounced, and sustained improvement in patients so severely affected by MICCH is unlikely to be caused solely by the placebo effect. All participants were disabled by the condition and had a long and unremitting history of frequent severe attacks of cluster headache, which did not respond to multiple conventional treatments. During the prospective 12-week baseline observation period, attack frequency and intensity were confirmed to be high and persistent, with little spontaneous variation over time. The possibility that there is little response to placebo in people with $\mathrm{MICHH}$ is in
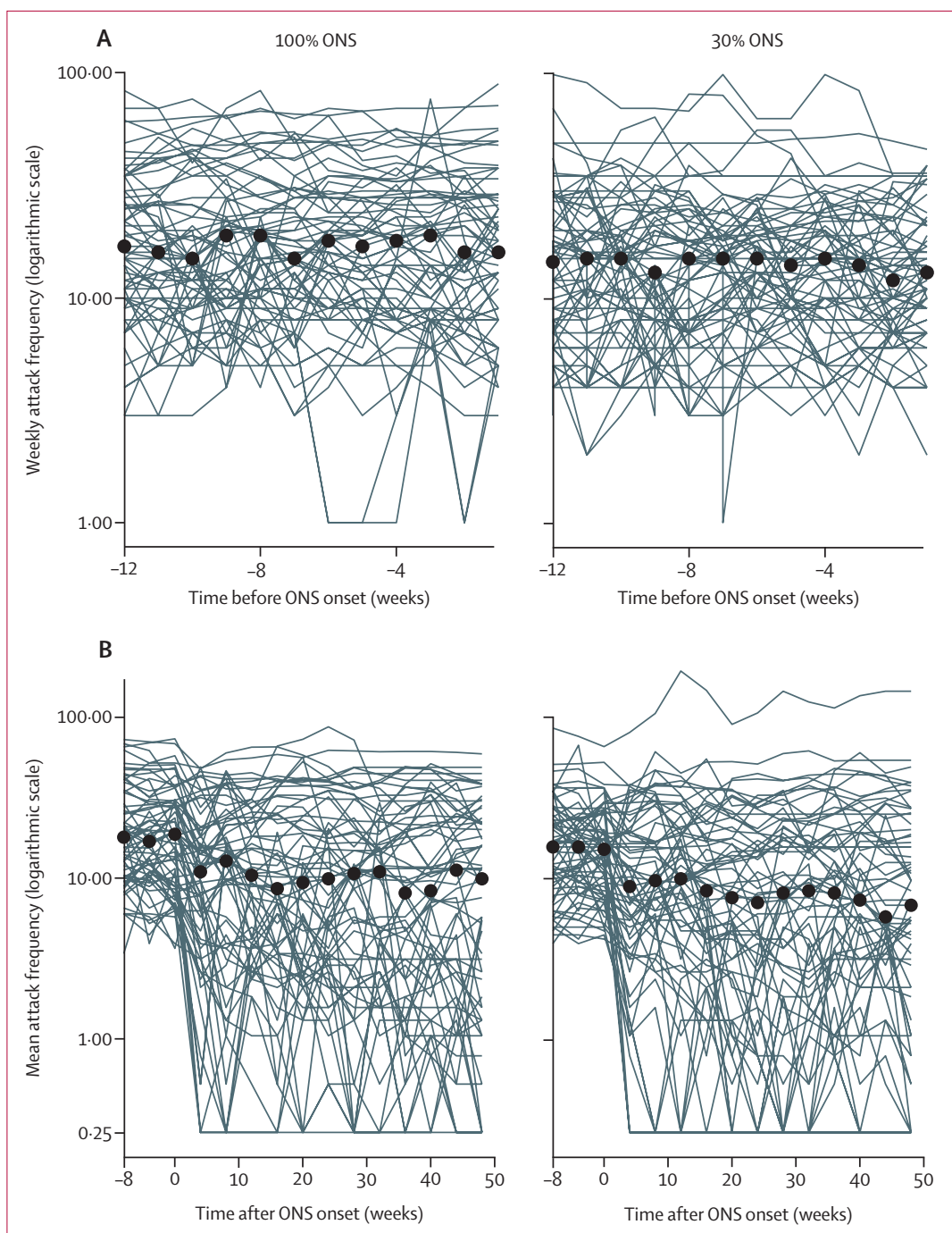

Figure 3: Attack frequency at baseline (A) and throughout the study period (B)

(A) Baseline individual weekly attack frequencies on a logaritmic scale during the 12 -week baseline observation period for the $100 \%$ ONS and 30\% ONS groups. The dots represent the means of the weekly attack frequencies in the previous week. (B) Individual MAF throughout the entire study period per 4-week treatment periods (12 weeks baseline observation, 24 weeks double-blind $100 \%$ ONS or $30 \%$ ONS, and 24 weeks open-label individually optimised ONS) on a logaritmic scale for the $100 \%$ ONS and $30 \%$ ONS groups. Note that between randomisation after the 12-week baseline observation period and day 0 of the double-blind ONS treatment period, there was a 10-day run-in phase with $10 \%$ ONS, which is not indicated in the figure because no data were collected for that period. The dots represent the means of the MAFs in the previous 4 weeks. Due to the logaritmic scale, the $43 \%$ median decrease in MAF shortly after ONS onset seems visually less substantial than on a linear scale. $M A F=$ mean attack frequencies. $\mathrm{ONS}=$ occipital nerve stimulation.

line with the negligible sham response in deep-brain stimulation in $\mathrm{MICCH}^{33}$ and the $24 \%$ placebo response in chronic (but not medically intractable) cluster headache. ${ }^{12}$ The placebo response in the study by Dodick and colleagues ${ }^{12}$ was less than half that observed in our study, which also included patients who were treatment resistant (and thus less likely to respond). Furthermore, placebo was administered by subcutaneous injection in a hospital, every month for 3 months, ${ }^{12}$ which would be expected to raise placebo response due to enhanced attention. In 


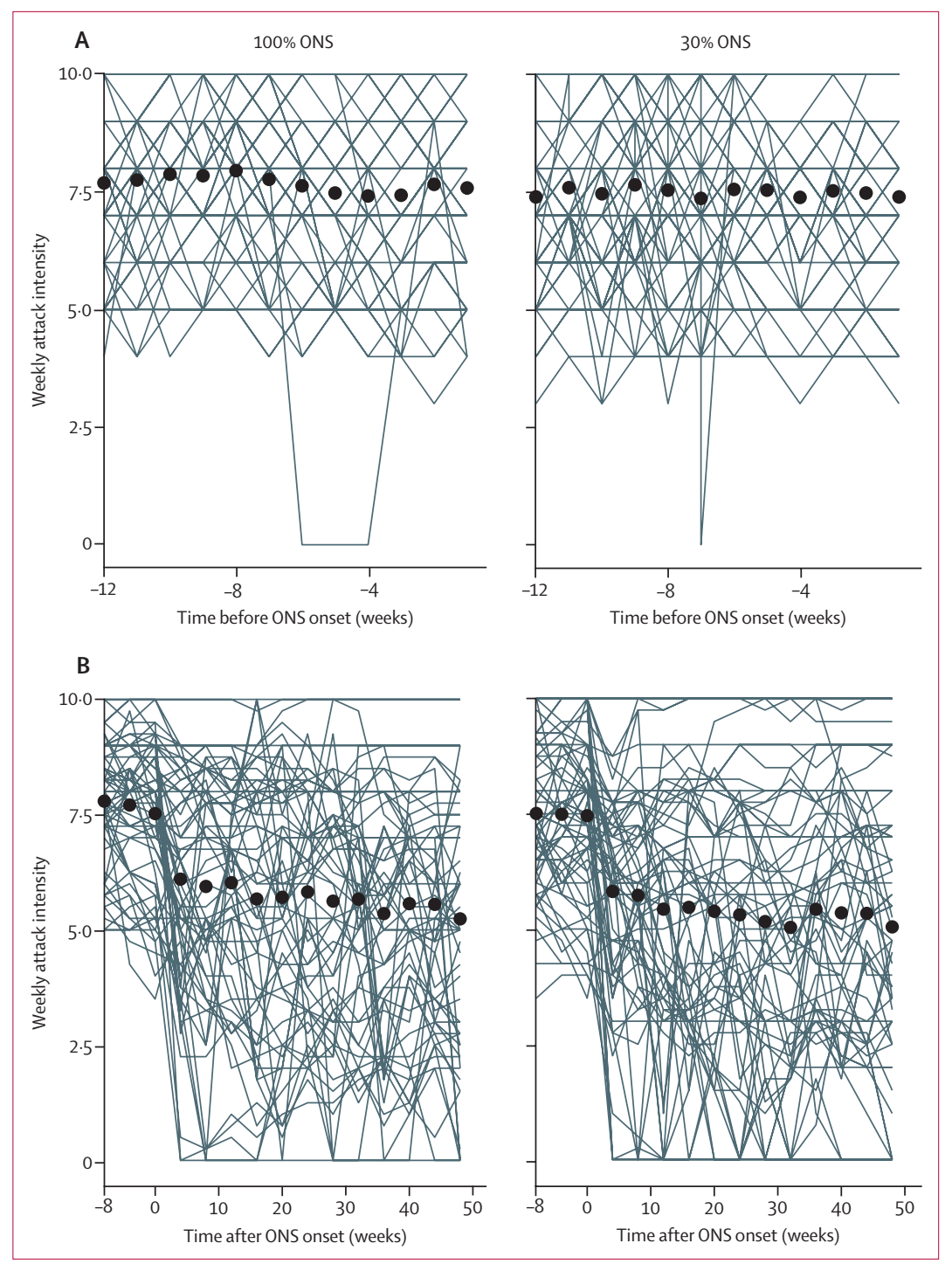

Figure 4: Attack intensity at baseline (A) and throughout the study period (B)

(A) Baseline individual weekly attack intensities in the 12 -week baseline observation period for the $100 \%$ ONS and $30 \%$ ONS groups. The dots represent the means of the weekly attack intensities in the previous week. (B) Individual mean attack intensities per 4-week periods ( 12 weeks baseline observation, 24 weeks double-blind $100 \%$ ONS or $30 \%$ ONS, and 24 weeks open-label individually optimised ONS) for the 100\% ONS and 30\% ONS groups for the entire study period. Note that between randomisation immediately after the 12 -week baseline observation period and day 0 of the double-blind ONS treatment period, there was a 10-day run-in phase with $10 \%$ ONS, which is not indicated in the figure because no data were collected for that period. The dots represent the means of the mean attack intensities in the previous 4 weeks. ONS=occipital nerve stimulation.

summary, although surgical interventions can be associated with large placebo responses, attributing the marked and sustained improvement of symptoms in the ICON study to the placebo effect following only one surgical intervention seems unlikely. Moreover, drivers of the placebo effect $\mathrm{t}^{34,35}$ do not seem to have substantially contributed.

High expectation might strongly promote placebo response, ${ }^{34,35}$ but is unlikely to have a major role in the present study. Participants were told that half of them would first receive low-intensity ONS, a potentially less effective form of ONS with similar paraesthesia, and that all participants would then get an individually optimised and thus potentially more effective form of ONS in the second half of the study. However, improvement was robust and similar during both study periods. There were no new participants with a reduction of at least $50 \%$ in MAF during the open-label period.

Personal attention and interaction with research staff and doctors are other potential reasons contributing to improvement. ${ }^{34,35}$ However, both personal attention and interaction were most intensive during the baseline and double-blind study periods, and patients received less interaction with members of research staff and doctors during the open-label phase because follow-up visits were less frequent. Despite this decline in personal attention, symptom improvement did not diminish.

We took measures to mitigate placebo response. ${ }^{36}$ We asked participants and investigators about presumed group assignment 24 weeks and 48 weeks after implantation. Study visits were done in accordance with the study protocol, with standardised questions. Furthermore, all study physicians were trained to standardise information about the benefit-risk profile and side-effects of the treatment. $^{36}$

Regression to the mean (spontaneous remission in patients with fluctuating disease severity who enter a therapeutic study when the disease is at its worst) and Hawthorne effects (changes in baseline conditions due to participants' awareness of being under study) are important non-therapeutic reasons for clinical improvement. ${ }^{34,35}$ However, during the 12-week prospective baseline period, attack frequency and intensity remained consistently high and in line with disease history. There was no sign of spontaneous improvement before treatment onset, rendering regression to the mean or Hawthorne effects unlikely. Improvement started only after ONS onset, similar to pain relief beginning after initiation of spinal cord stimulation in various indications. ${ }^{37}$

Finally, although placebo responses can persist for long periods, ${ }^{38}$ the duration of sustained improvement is exceeding what can reasonably be expected of a placebo response. At the end of the 24-week open-label extension phase, none of the patients who had a $50 \%$ or greater reduction in MAF in the double-blind phase had deteriorated, and some had improved even further. Long-term follow-up data show sustained response for up to 9 years (data to be published), in line with a French multicentre prospective data registry regarding long-term efficacy of ONS in 105 patients with MICCH. ${ }^{22}$ More information about placebo responses in MICCH might come from future studies that use paraesthesia-free (sub-threshold) burst stimulation, which has shown promising results ${ }^{39}$ but was not available when we started our study.

We can only speculate why $30 \%$ ONS and $100 \%$ ONS had similar efficacy. Both intensities caused similar paraesthesia. These findings seem to support the clinical observation that ONS might be effective at or below the lowest intensity that induces paraesthesia. If true, this 
would suggest a maximum effect of ONS in inhibiting the trigeminocervical complex.

Future studies should shed more light on the mode and timing of onset of action of ONS in $\mathrm{MICCH}$, in particular that of low-amplitude ONS. Although the effect size in our study was in line with those seen in earlier open-label ONS studies, ${ }^{1422}$ the onset of improvement in our study was faster than in other studies. A post-hoc analysis revealed that median MAF had decreased to $8 \cdot 0$ (IQR 3.0-16.5) in the first week after the $10 \%$ ONS run-in phase. During the first week of the double-blind phase, half the participants remained on $10 \%$ ONS while the other half had only just increased to $40 \%$ ONS. This contradicts an important role for network plasticity adaptation, because this would require some time. ${ }^{17}$ Because we did not monitor MAF in the run-in phase, we cannot exclude the possibility that some patients had already improved at $10 \%$ stimulation.

The rapid improvement in cluster headache symptoms we observed after ONS treatment is similar to what is often seen after high oral doses of corticosteroids ${ }^{2}$ or subcutaneous injections of corticosteroids around the greater occipital nerve. ${ }^{40,41}$ Non-invasive vagus nerve stimulation can also rapidly improve chronic cluster headache,${ }^{30}$ but there are no data on its efficacy in MICCH. In fact in our study, early improvement seems to predict long-term sustained efficacy. MAF in weeks 1-4 was highly predictive of success at weeks $21-24$ ( $<<0 \cdot 001)$. Further analyses, using more complex predictive factors, ${ }^{42}$ will be the subject of a future publication.

During the masked study period, a third of participants had a serious adverse event, a proportion that is similar to other ONS studies. ${ }^{43}$ Two thirds of these events consisted of replacing an empty IPG or a dislocated or fractured electrode or lead. In this context, it is important to realise that the hardware we used in the study was developed for epidural spinal cord stimulation. However, the bending forces in ONS are much greater, increasing the risk of fracture or dislocation. In the course of the study a more flexible electrode, that was better adjustable to the shape of the skull and more resistant to migration, became available. However, for consistency, we decided to use the improved electrodes only for replacements in participants who had completed the double-blind phase of the study. Similarly, when we started the study we used non-rechargeable IPGs. Because power consumption was unexpectedly high, IPG depletion sometimes occurred earlier than expected. To preclude protocol deviations during the double-blind phase, we decided to use rechargeable IPGs only for replacements. Importantly, most serious adverse events were related to hardware replacements, only requiring minor surgery and 1 day hospitalisation. However, according to formal guidelines, these events still had to be labelled as serious adverse events.

Apart from adverse events, other study limitations should be considered. First, we did not show a difference in patient response between high and low ONS and must, therefore, rely on circumstantial evidence for efficacy. However, this evidence seems, to us, convincing. Second, due to reimbursement issues (appendix p 8) patient enrolment took longer than expected, although this gave us the opportunity to collect long-term follow-up data while the ICON study was still ongoing, which will be published at a later date. Third, in 20 participants in

\begin{tabular}{|c|c|c|c|c|c|c|}
\hline & \multicolumn{4}{|c|}{ Masked study phase } & \multirow{2}{*}{\multicolumn{2}{|c|}{$\begin{array}{l}\text { Open-label study phase } \\
\text { Total patient population } \\
(\mathrm{n}=128)\end{array}$}} \\
\hline & \multicolumn{2}{|c|}{$\begin{array}{l}100 \% \text { ONS stimulation } \\
(n=65)\end{array}$} & \multicolumn{2}{|c|}{$\begin{array}{l}30 \% \text { ONS stimulation } \\
(n=65)\end{array}$} & & \\
\hline & $\begin{array}{l}\text { Number of } \\
\text { events }\end{array}$ & $\begin{array}{l}\text { Patients with } \\
\text { events }\end{array}$ & $\begin{array}{l}\text { Number of } \\
\text { events }\end{array}$ & $\begin{array}{l}\text { Patients with } \\
\text { events }\end{array}$ & $\begin{array}{l}\text { Number of } \\
\text { events }\end{array}$ & $\begin{array}{l}\text { Patients with } \\
\text { events }\end{array}$ \\
\hline $\begin{array}{l}\text { Serious adverse } \\
\text { events }\end{array}$ & 17 & $15(23 \%)$ & 8 & $7(11 \%)$ & 34 & $30(23 \%)$ \\
\hline \multicolumn{7}{|c|}{ Hardware-related serious adverse events } \\
\hline Total & 9 & $8(12 \%)$ & 5 & $4(6 \%)$ & 21 & $20(16 \%)$ \\
\hline Lead migration & 3 & $3(5 \%)$ & 3 & $3(5 \%)$ & 3 & $2(2 \%)$ \\
\hline Replacement IPG & 2 & $2(3 \%)$ & 0 & 0 & 8 & $8(6 \%)$ \\
\hline $\begin{array}{l}\text { Replacement lead } \\
\text { or cable }\end{array}$ & 4 & $3(5 \%)$ & 2 & $1(2 \%)$ & 10 & $10(8 \%)$ \\
\hline \multicolumn{7}{|c|}{ Serious adverse events related to biological complications } \\
\hline Total & 5 & $4(6 \%)$ & 2 & $2(3 \%)$ & 9 & $8(6 \%)$ \\
\hline $\begin{array}{l}\text { Impaired wound } \\
\text { healing }\end{array}$ & 2 & $2(3 \%)$ & 2 & $2(3 \%)$ & 2 & $2(2 \%)$ \\
\hline $\begin{array}{l}\text { Explantation of } \\
\text { device }\end{array}$ & 0 & 0 & 0 & 0 & 5 & $5(4 \%)$ \\
\hline Local pain & 3 & $2(3 \%)$ & 0 & 0 & 2 & $2(2 \%)$ \\
\hline \multicolumn{7}{|c|}{ Other types of serious adverse event } \\
\hline Total & 3 & $3(5 \%)$ & 1 & $1(2 \%)$ & 4 & $4(3 \%)$ \\
\hline $\begin{array}{l}\text { Chest } \\
\text { palpitations }\end{array}$ & 2 & $2(3 \%)$ & 0 & 0 & 0 & 0 \\
\hline Fever & 0 & 0 & 1 & $1(2 \%)$ & 0 & 0 \\
\hline $\begin{array}{l}\text { Transient } \\
\text { ischaemic attack }\end{array}$ & 1 & $1(2 \%)$ & 0 & 0 & 0 & 0 \\
\hline Headache & 0 & 0 & 0 & 0 & 1 & $1(1 \%)$ \\
\hline $\begin{array}{l}\text { Cardiac } \\
\text { pacemaker* }\end{array}$ & 0 & 0 & 0 & 0 & 2 & $2(2 \%)$ \\
\hline $\begin{array}{l}\text { Pulmonary tract } \\
\text { infection }\end{array}$ & 0 & 0 & 0 & 0 & 1 & $1(1 \%)$ \\
\hline $\begin{array}{l}\text { Non-serious } \\
\text { adverse events }\end{array}$ & 112 & $48(74 \%)$ & 87 & $43(66 \%)$ & 52 & $38(30 \%)$ \\
\hline \multicolumn{7}{|c|}{ Adverse events related to biological complications $\dagger$} \\
\hline Total & 68 & $38(58 \%)$ & 48 & $29(45 \%)$ & 15 & $11(9 \%)$ \\
\hline $\begin{array}{l}\text { Impaired wound } \\
\text { healing }\end{array}$ & 13 & $7(11 \%)$ & 7 & $4(6 \%)$ & 2 & $2(2 \%)$ \\
\hline $\begin{array}{l}\text { Stiffness of } \\
\text { the neck }\end{array}$ & 10 & $9(14 \%)$ & 10 & $10(15 \%)$ & 5 & $5(4 \%)$ \\
\hline Local pain & 36 & $24(37 \%)$ & 27 & $20(31 \%)$ & 3 & $3(2 \%)$ \\
\hline $\begin{array}{l}\text { Itching around } \\
\text { scar }\end{array}$ & 0 & 0 & 1 & $1(2 \%)$ & 0 & 0 \\
\hline Paraesthesia & 6 & $6(9 \%)$ & 3 & $3(5 \%)$ & 4 & $4(3 \%)$ \\
\hline Other headache $\neq$ & 1 & $1(2 \%)$ & 0 & 0 & 1 & $1(1 \%)$ \\
\hline $\begin{array}{l}\text { Sleeping } \\
\text { problems due to } \\
\text { paraesthesia }\end{array}$ & 1 & $1(2 \%)$ & 0 & 0 & 0 & 0 \\
\hline $\begin{array}{l}\text { Balance problems } \\
\text { after surgery }\end{array}$ & 1 & $1(2 \%)$ & 0 & 0 & 0 & 0 \\
\hline
\end{tabular}




\begin{tabular}{|c|c|c|c|c|c|c|}
\hline & \multicolumn{4}{|c|}{ Masked study phase } & \multirow{2}{*}{\multicolumn{2}{|c|}{$\begin{array}{l}\text { Open-label study phase } \\
\begin{array}{l}\text { Total patient population } \\
(\mathrm{n}=128)\end{array}\end{array}$}} \\
\hline & \multicolumn{2}{|c|}{$\begin{array}{l}100 \% \text { ONS stimulation } \\
(\mathrm{n}=65)\end{array}$} & \multicolumn{2}{|c|}{$\begin{array}{l}30 \% \text { ONS stimulation } \\
(n=65)\end{array}$} & & \\
\hline & $\begin{array}{l}\text { Number of } \\
\text { events }\end{array}$ & $\begin{array}{l}\text { Patients with } \\
\text { events }\end{array}$ & $\begin{array}{l}\text { Number of } \\
\text { events }\end{array}$ & $\begin{array}{l}\text { Patients with } \\
\text { events }\end{array}$ & $\begin{array}{l}\text { Number of } \\
\text { events }\end{array}$ & $\begin{array}{l}\text { Patients with } \\
\text { events }\end{array}$ \\
\hline \multicolumn{7}{|c|}{ (Continued from previous page) } \\
\hline \multicolumn{7}{|c|}{ Hardware-related non-serious adverse events $\S$} \\
\hline Total & 10 & $9(14 \%)$ & 7 & $7(11 \%)$ & 19 & $17(13 \%)$ \\
\hline $\begin{array}{l}\text { Damage to the } \\
\text { lead, cable, or } \\
\text { electrode }\end{array}$ & 10 & $9(14 \%)$ & 7 & $7(11 \%)$ & 18 & $16(13 \%)$ \\
\hline $\begin{array}{l}\text { Anchors located } \\
\text { superficially }\end{array}$ & 0 & 0 & 0 & 0 & 1 & $1(1 \%)$ \\
\hline \multicolumn{7}{|c|}{ Unknown adverse events related to treatment $\boldsymbol{\Phi}$} \\
\hline Total & 11 & $9(14 \%)$ & 7 & $5(8 \%)$ & 4 & $4(3 \%)$ \\
\hline \multicolumn{7}{|c|}{ Other adverse events, probably unrelated to treatment } \\
\hline Total & 23 & $18(28 \%)$ & 25 & $21(32 \%)$ & 14 & $11(9 \%)$ \\
\hline \multicolumn{7}{|c|}{$\begin{array}{l}\text { IPG=implantable pulse generator. ONS=occipital nerve stimulation. Explantation was due to pain }(n=4) \text { or no preventive } \\
\text { effect on cluster headache attacks }(n=1) \text {. *Adverse event due to the placement of the cardiac pacemaker, such as } \\
\text { bradycardia caused by high-dose verapamil }(n=1) \text { and treatment of pre-existent cardiac illness }(n=1) \text {. †Biological } \\
\text { complications like transient pain or sensitivity at IPG region, painful paraesthesia, or transient stiffness of the neck region. } \\
\text { ¥Other headache type, such as development of occipital neuralgia }(n=1) \text { and tension-type headache }(n=1) \text {. } \\
\text { SHardware-related adverse event, such as broken contact point of one of the leads, without effect on stimulation area. } \\
\text { IExpected biological complications or device-related adverse event, which was not serious and was not further specified. }\end{array}$} \\
\hline
\end{tabular}

the $100 \%$ stimulation group, prespecified ONS intensities had to be lowered because of discomfort. However, per-protocol analysis did not reveal significant differences from the intention-to-treat analysis.

The ICON study also has many strengths. First, the baseline period is considerably longer than usual (2-4 weeks at most). ${ }^{10,33,40,44}$ This extended period allowed for a more accurate estimation of the attack frequency at baseline and showed that there was no spontaneous decrease in attack frequency in the first 12 weeks after inclusion (but before treatment onset), rendering regression to the mean or Hawthorne effects unlikely. Other strengths of our study include the low dropout rate and few missing values strengthening the validity of the results. Finally, we took great care in harmonising the implantation procedures across centres to minimise surgical variability. All individuals who implanted the devices were trained, and their first study implantations were supervised by expert members of the steering committee.

Other forms of neuromodulation, such as deep brain stimulation $^{6}$ and high-volume anaesthetic suboccipital nerve blocks, ${ }^{45}$ have also shown some efficacy in $\mathrm{MICCH}$, but primarily in small case series. In the only randomised controlled study, ${ }^{33}$ double-blind deep-brain stimulation for 1 month was not superior to sham treatment. After 10 months of open-label treatment, however, six of 11 patients had improved. Routine use of deep-brain stimulation is hampered by severe and even fatal complications. ${ }^{8}$ In a post-hoc analysis of a sham-controlled study on the acute effects of invasive sphenopalatine ganglion stimulation in chronic cluster headache, repeated stimulation seemed to reduce attack frequency. ${ }^{44}$ Finally, add-on, noninvasive vagal-nerve stimulation reduced attack frequency in cluster headache compared with standard care plus sham. ${ }^{30}$ The response of patients in the control group was low. Whether this therapy is effective in $\mathrm{MICCH}$ is unknown.

In conclusion, although the results of our study did not show a difference in treatment response between the different groups, circumstantial evidence suggests that ONS is an effective, well tolerated, and safe last-resort therapy for $\mathrm{MICCH}$, even at electrical doses that are lower than those currently recommended in the field of neurostimulation. Our results confirm the effects seen in small studies that did not include a comparator group. ${ }^{14-20}$ Placebo response cannot be excluded, but seems unlikely to have had a major role, given the marked, long-term, and sustained improvement in patients who, for many years, had been highly disabled due to frequent, unremitting attacks of cluster headache, despite the patients having tried multiple preventive drugs. The stable high attack frequency during the 12-week baseline period renders regression to the mean or Hawthorne effects unlikely. The majority of participants were highly satisfied and would strongly recommend ONS to other patients. Future biophysical and biomedical studies should focus on the mode of action of ONS, in particular at low intensity, and on improved stimulation protocols and trial designs to test them.

\section{Contributors}

FJPMH, LAW, OPMT, WMM, JH, GHS, and MDF designed the study. LAW, IFdC, PGGD, and MDF did the literature search and created the figures. The study data were collected by FJPMH, LAW, IFdC, PGGD, OPMT, KB, RTMvD, WMM, JH, ECB, FW, EK, GHS, and MDF, analysed by FJPMH, LAW, IFdC, PGGD, EWvZ, WMM, and MDF, and interpreted by FJPMH, LAW, IFdC, PGGD, OPMT, WMM, JH, GHS, and MDF. This report was written by LAW, IFdC, PGGD, OPMT, RTMvD, WMM, JH, FJPMH, and MDF after the underlying data were verified by LAW, IFdC, and PGGD.

\section{Declaration of interests}

MDF reports grants and consultancy or industry support from Electrocore, Medtronic, Eli Lilly, Amgen, Novartis, and TEVA, and independent support from The Netherlands Organisation for Scientific Research, The Netherlands Organisation for Health Research and Development, The Dutch Brain and Heart Foundations, The Dutch Ministry of Health, and The NutsOhra Foundation from the Dutch Insurance Companies. FJPMH reports grants and consultancy fees from Abbott, Saluda, and Pfizer, and independent support from The Netherlands Organisation for Health Research and Development. IFdC reports travel grants from Electrocore. All other authors report no competing interests.

\section{Data sharing}

The data used for this study, including de-identified individual data and a data dictionary defining each field within the dataset, can be made available on a secure server by the corresponding author on reasonable request. These data will be made available only after full-text publication of the primary trial report. Written proposals, including specific requirements, rationale, and proposed use will be evaluated by the trial steering committee, who will give a decision regarding the suitability and appropriateness of the use of data. Shared data must be used only for academic and non-commercial purposes. A data-sharing agreement must be signed before any data are shared.

\section{Acknowledgments}

We gratefully acknowledge logistical support from Dr R Buschman (Medtronic BV, Eindhoven, Netherlands). The study was funded by the Spinoza 2009 Lifetime Scientific Research Achievement Premium from 
the Netherlands Organisation for Scientific Research, the Dutch Ministry of Health (as part of a national provisional reimbursement programme for promising new treatments), the NutsOhra Foundation from the Dutch Health Insurance Companies, and an unrestricted grant from Medtronic, all to MDF. The corresponding author had full access to all the data in the study and had final responsibility for the decision to sumit for publication.

References

1 Headache Classification Committee of the International Headache Society. The international classification of headache disorders, 3rd edn. Cephalalgia 2018; 38: 1-211.

2 Hoffmann J, May A. Diagnosis, pathophysiology, and management of cluster headache. Lancet Neurol 2018; 17: 75-83.

3 Goadsby PI, Schoenen J, Ferrari MD, et al. Towards a definition of intractable headache for use in clinical practice and trials. Cephalalgia 2006; 26: 1168-70.

4 Mitsikostas DD, Edvinsson L, Jensen RH, et al. Refractory chronic cluster headache: a consensus statement on clinical definition from the European Headache Federation. J Headache Pain 2014; 15: 79.

5 Rozen TD, Fishman RS. Cluster headache in the United States of America: demographics, clinical characteristics, triggers, suicidality, and personal burden. Headache 2012; 52: 99-113.

6 Vyas DB, Ho AL, Dadey DY, et al. Deep brain stimulation for chronic cluster headache: a review. Neuromodulation 2019; 22: 388-97.

7 Nowacki A, Schober M, Nader L, et al. Deep brain stimulation for chronic cluster headache: meta-analysis of individual patient data. Ann Neurol 2020; 88: 956-69.

8 Schoenen J, Di Clemente L, Vandenheede M, et al. Hypothalamic stimulation in chronic cluster headache: a pilot study of efficacy and mode of action. Brain 2005; 128: 940-47.

9 Charles A, Pozo-Rosich P. Targeting calcitonin gene-related peptide: a new era in migraine therapy. Lancet 2019; 394: 1765-74.

10 Goadsby PJ, Dodick DW, Leone M, et al. Trial of galcanezumab in prevention of episodic cluster headache. N Engl J Med 2019; 381: $132-41$.

11 Gelfand AA, Goadsby PJ. Cluster headache and calcitonin gene-related peptide: more on quantum therapeutics in headache medicine. JAMA Neurol 2018; 75: 1179-80.

12 Dodick DW, Goadsby PJ, Lucas C, et al. Phase 3 randomized, placebo-controlled study of galcanezumab in patients with chronic cluster headache: results from 3-month double-blind treatment. Cephalalgia 2020; 40: 935-48.

13 Wilbrink LA, Teernstra OP, Haan J, et al. Occipital nerve stimulation in medically intractable, chronic cluster headache. The ICON study: rationale and protocol of a randomised trial. Cephalalgia 2013; 33: 1238-47.

14 Miller S, Watkins L, Matharu M. Treatment of intractable chronic cluster headache by occipital nerve stimulation: a cohort of 51 patients. Eur J Neurol 2017; 24: 381-90.

15 Burns B, Watkins L, Goadsby PJ. Treatment of intractable chronic cluster headache by occipital nerve stimulation in 14 patients. Neurology 2009; 72: 341-45.

16 Fontaine D, Christophe SJ, Raoul S, et al. Treatment of refractory chronic cluster headache by chronic occipital nerve stimulation. Cephalalgia 2011; 31: 1101-05.

17 Magis D, Allena M, Bolla M, et al. Occipital nerve stimulation for drug-resistant chronic cluster headache: a prospective pilot study. Lancet Neurol 2007; 6: 314-21.

18 Magis D, Gerardy PY, Remacle JM, et al. Sustained effectiveness of occipital nerve stimulation in drug-resistant chronic cluster headache. Headache 2011; 51: 1191-201.

19 Magis D, Gerard P, Schoenen J. Invasive occipital nerve stimulation for refractory chronic cluster headache: what evolution at long-term? Strengths and weaknesses of the method. J Headache Pain 2016; 17: 8

20 Burns B, Watkins L, Goadsby PJ. Treatment of medically intractable cluster headache by occipital nerve stimulation: long-term follow-up of eight patients. Lancet 2007; 369: 1099-106.

21 Aibar-Duran JA, Alvarez Holzapfel MJ, Rodriguez Rodriguez R, et al. Occipital nerve stimulation and deep brain stimulation for refractory cluster headache: a prospective analysis of efficacy over time. J Neurosurg 2020; 1: 1-8.

22 Leplus A, Fontaine D, Donnet A, et al. Long-term efficacy of occipital nerve stimulation for medically intractable cluster headache. Neurosurgery 2021; 88: 375-83.
23 Trentman TL ZR, Seth N, Hentz JG, et al. Stimulation ranges, usage ranges, and paresthesia mapping during occipital nerve stimulation. Neuromodulation 2008; 11: 56-61.

24 Moran F, Leonard T, Hawthorne S, et al. Hypoalgesia in response to transcutaneous electrical nerve stimulation (TENS) depends on stimulation intensity. J Pain 2011; 12: 929-35.

25 Lazarou L, Kitsios A, Lazarou I, et al. Effects of intensity of transcutaneous electrical nerve stimulation (TENS) on pressure pain threshold and blood pressure in healthy humans: a randomized, double-blind, placebo-controlled trial. Clin J Pain 2009; 25: 773-80.

26 Ben Menachem E, Manon-Espaillat R, Ristanovic R, et al. Vagus nerve stimulation for treatment of partial seizures: a controlled study of effect on seizures. Epilepsia 1994; 35: 616-26.

27 Matharu MS, Bartsch T, Ward N, et al. Central neuromodulation in chronic migraine patients with suboccipital stimulators: a PET study. Brain 2004; 127: 220-30.

28 Headache Classification Committee of the International Headache Society. The international classification of headache disorders, 2nd edn. Cephalalgia 2004; 24: 9-160.

29 de Coo IF, Wilbrink LA, Haan J. Symptomatic trigeminal autonomic cephalalgias. Curr Pain Headache Rep 2015; 19: 514

30 Gaul C, Diener HC, Silver N, et al. Non-invasive vagus nerve stimulation for PREVention and Acute treatment of chronic cluster headache (PREVA): a randomised controlled study. Cephalalgia 2016; 36: 534-46.

31 Williamson A, Hoggart B. Pain: a review of three commonly used pain rating scales. J Clin Nurs 2005; 14: 798-804.

32 Markus R, Peritz E, Gabriel KR. On closed testing procedures with special reference to ordered analysis of variance. Biometrika 1976; 63: 655-60.

33 Fontaine D, Lazorthes Y, Mertens P, et al. Safety and efficacy of deep brain stimulation in refractory cluster headache: a randomized placebo-controlled double-blind trial followed by a 1-year open extension. J Headache Pain 2010; 11: 23-31.

34 Kaptchuk TJ, Miller FG. Placebo effects in medicine. N Engl J Med 2015; 373: 8-9.

35 Benedetti F, Carlino E, Piedimonte A. Increasing uncertainty in CNS clinical trials: the role of placebo, nocebo, and Hawthorne effects. Lancet Neurol 2016; 15: 736-47.

36 Colloca L, Barsky AJ. Placebo and nocebo effects. N Engl J Med 2020; 382: 554-61.

37 Kapural L. Spinal cord stimulation for intractable chronic pain. Curr Pain Headache Rep 2014; 18: 406.

38 Wartolowska KA, Feakins BG, Collins GS, et al. The magnitude and temporal changes of response in the placebo arm of surgical randomized controlled trials: a systematic review and meta-analysis. Trials 2016; 17: 589.

39 Garcia-Ortega R, Edwards T, Moir L, et al. Burst occipital nerve stimulation for chronic migraine and chronic cluster headache. Neuromodulation 2019; 22: 638-44.

40 Ambrosini A, Vandenheede M, Rossi P, et al. Suboccipital injection with a mixture of rapid- and long-acting steroids in cluster headache: a double-blind placebo-controlled study. Pain 2005; 118: 92-96.

41 Leroux E, Valade D, Taifas I, et al. Suboccipital steroid injections for transitional treatment of patients with more than two cluster headache attacks per day: a randomised, double-blind, placebo-controlled trial. Lancet Neurol 2011; 10: 891-97.

42 Miller S, Watkins L, Matharu M. Predictors of response to occipital nerve stimulation in refractory chronic headache. Cephalalgia 2018; 38: 1267-75.

43 Sharan A, Huh B, Narouze S, et al. Analysis of adverse events in the management of chronic migraine by peripheral nerve stimulation. Neuromodulation 2015; 18: 305-12.

44 Goadsby PJ, Sahai-Srivastava S, Kezirian EJ, et al. Safety and efficacy of sphenopalatine ganglion stimulation for chronic cluster headache: a double-blind, randomised controlled trial. Lancet Neurol 2019; 18: 1081-90.

45 Rozen TD. High-volume anesthetic suboccipital nerve blocks for treatment refractory chronic cluster headache with long-term efficacy data: an observational case series study. Headache 2019; 59: 56-62. 